\title{
WITHDRAWN: Commentary: Time may heal, but a word of caution is advised
}

James D. St Louis, MD, ${ }^{\mathrm{a}}$ and Mark D. Plunkett, $\mathrm{MD}^{\mathrm{b}}$

${ }^{a}$ Department of Surgery, University of Missouri-Kansas City School of Medicine, Kansas City, Mo

${ }^{\mathrm{b}}$ Congenital Heart Center, Children's Hospital of Illinois, Peoria, Ill

This article has been withdrawn at the request of the author(s) and/or editor. The Publisher apologizes for any inconvenience this may cause.

The full Elsevier Policy on Article Withdrawal can be found at https://www.elsevier.com/about/ourbusiness/policies/article-withdrawal 